\title{
Energy Deposition in Metals by Laser-Guided Discharges
}

\author{
M. L. Brake, ${ }^{1}$ R. M. Gilgenbach, ${ }^{1}$ L. D. Horton, ${ }^{1}$ \\ and J. E. Tucker ${ }^{1}$ \\ Received May 6, 1983; revised August 12, 1983
}

\begin{abstract}
Experimental and theoretical results are reported concerning energy deposition on metal surfaces by laser-guided discharges (LGD) in argon and nitrogen at atmospheric pressure. These experiments have demonstrated effective guidance of $30-k \mathrm{~V}$ discharges for lengths up to $6 \mathrm{~cm}$. The electron temperature and density have been measured spectroscopically for LGD plasmas. Scaling of the melted metallic mass has been studied as a function of discharge circuit parameters for both argon and nitrogen. Results show that laser-guided discharges in nitrogen couple energy to metal samples more efficiently than argon discharges with identical electrical parameters. This experimentally observed difference in energy deposition has been shown to be in good agreement with a theoretical model which accounts for the recombination energy of nitrogen on the metallic surface. Melting has been accomplished by LGDs in copper, iron, aluminum, and titanium foils. Laser-guided discharges have also bored holes and deposited surface layers of aluminum and titanium onto stainless steel.
\end{abstract}

KEY WORDS: Laser-guided discharges; hole boring; surface deposition; electrical discharge.

\section{INTRODUCTION}

Extensive research has been performed at other laboratories concerning the properties of high voltage $(>100 \mathrm{kV})$ discharges guided over distances of several meters by laser-induced breakdown of atmospheric-pressure gas. ${ }^{(1-4)}$ More recently, we have shown that lower-voltage $(30 \mathrm{kV})$ discharges guided over several centimeters by laser-induced gas breakdown can deposit discharge energy in metallic surfaces. ${ }^{(5)}$

In order to guide an electrical discharge, a pulsed $\mathrm{CO}_{2}$ laser is focused to a designated point on the metal sample electrode. The laser induces a gas-breakdown plasma between the metal sample electrode and a second

\footnotetext{
${ }^{1}$ Nuclear Engineering Department, The University of Michigan, Ann Arbor, Michigan 48109.
} 
electrode. This laser-induced breakdown plasma provides a low impedance path for the high-voltage discharge. The region heated by the discharge can be scanned by changing only the laser spot position. The spot size of the deposited energy profile has been shown ${ }^{(5)}$ to be influenced by the delay between the laser pulse and the high-voltage discharge. By defocusing the $\mathrm{CO}_{2}$ laser spot, the melted region on a sample can be similarly defocused.

This new process could have important industrial applications to hole boring, welding, metal deposition, and localized heat treating of metals, all of which could be performed in atmospheric-pressure gas. Energy deposition by laser-guided discharges (LGD) has advantages over conventional laser processing in that the overall electrical efficiency is potentially much higher, especially in materials which exhibit high infrared reflectivity. Materials processing by LGD also has advantages over conventional electric discharge machining (EDM), since the LGD electrode is several centimeters from the workpiece and discharges can be guided to locations inaccessible to EDM.

In a previous paper, ${ }^{(5)}$ the basic characteristics of LGD energy deposition were demonstrated: scannability, dependence upon relative delay between laser and discharge, as well as focusing effects and hole boring in foils. The results reported here deal with experimental and theoretical investigations of energy deposition on metals by laser-guided discharges in monatomic gases (Ar and $\mathrm{He}$ ) versus a diatomic gas $\left(\mathrm{N}_{2}\right)$. The scaling of this energy deposition with discharge parameters has been studied in this research. Spectroscopic measurements have also been performed in order to characterize the discharge plasma temperature and density.

\section{EXPERIMENT AND DIAGNOSTICS}

The experimental configuration is depicted schematically in Fig. 1. The output of the TEA $\mathrm{CO}_{2}$ laser was focused by a $79 \mathrm{~cm}$ focal length germanium lens onto a flat electrode covered by the foil samples. The laser-guided discharges were generated in a Lucite chamber filled with gas at atmospheric pressure. Laser energy in these experiments was about $10 \mathrm{~J}$; of this energy, $60 \%$ was incident in an $80 \mathrm{~ns}$ base triangular pulse with the remaining energy in a low-intensity tail. The laser energy used here was larger than in the previous experiments in lab air, ${ }^{(5)}$ since the clean nitrogen breakdown threshold is higher than that for unfiltered air. This laser energy, after attenuation by the gas-breakdown plasma, did not damage the metal foils in the absence of the discharge.

In order to test the scaling of LGD energy deposition with circuit parameters, the discharge circuit was configured so that up to four highvoltage capacitors $(0.08 \mu \mathrm{F}$ each $)$ could be connected in parallel. Timing 


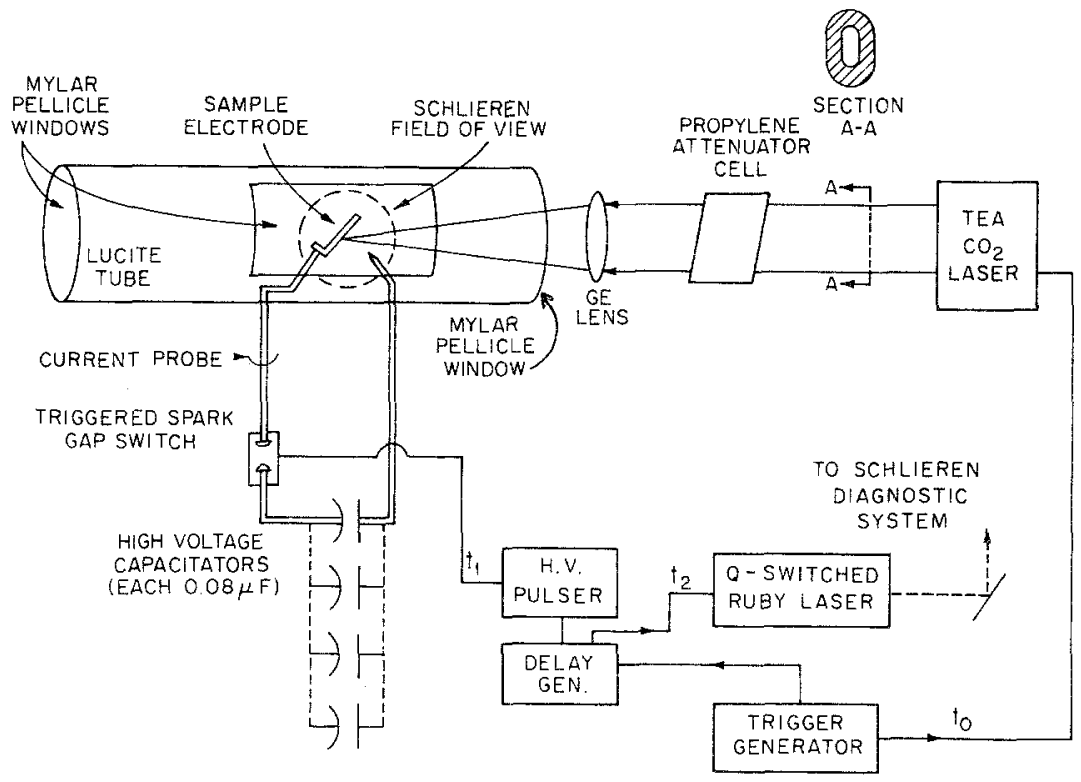

Fig. 1. Experimental configuration. Up to four capacitors were connected in parallel for these experiments. Capacitor charging voltage was $30 \mathrm{kV}$.

of the $\mathrm{CO}_{2}$ laser pulse was about $50 \mathrm{~ns}$ before the trigger to the spark-gap switch. This minimizes the diameter of the laser-induced breakdown plasma during the discharge current rise, which occurs $250 \mathrm{~ns}$ after the laser pulse.

A ruby laser schlieren diagnostic provided temporally and spatially resolved data concerning the discharge path. This schlieren system employed a 20-ns Q-switched ruby laser pulse, timed so that pictures were taken $1.2 \mu \mathrm{s}$ after the trigger to the spark gap and approximately $1 \mu \mathrm{s}$ after the discharge current rise. The schlieren system employed a 1-mm-diameter pinhole instead of the usual knife edge in order to obtain sensitivity to density gradients in two dimensions.

The laser-guided discharge energy deposition was characterized by covering the sample electrode by one or more layers of metal foil. These foil stacks were changed after each discharge, and the total displaced mass of metal was measured.

Time-integrated emission spectra were observed by means of a Jarrell Ash $0.75 \mathrm{~m}, f / 6.3$ grating spectrograph. Spectra were recorded on film and analyzed with a microdensitometer. Temporally resolved optical emission from the discharge was recorded using a fiber-optic cable coupled to a photomultiplier tube located in a Faraday cage. 


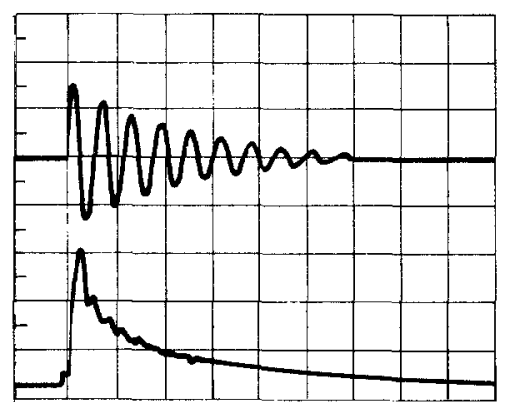

Fig. 2. Oscilloscope traces for laser-guided discharge with circuit capacitance of $0.24 \mu \mathrm{F}$. Upper trace: discharge current $(10 \mathrm{kA} / \mathrm{div}$.); lower trace: optical emission. Time scale is $5 \mu \mathrm{s} /$ div.

\section{EXPERIMENTAL RESULTS}

Typical discharge current and optical emission signals are shown in Fig. 2. Note that the optical emission signal shows the flash from laserinduced breakdown preceding the light from the discharge. The current traces were identical for nitrogen and argon discharges. The peak discharge current and ringing period depended upon the number of capacitors, ranging from $10 \mathrm{kA}$ peak with a $1.5 \mu$ s ringing period (one capacitor) to $18 \mathrm{kA}$ peak with a $3.7 \mu$ s ringing period (four capacitors).

Schlieren photographs of laser-guided discharges in argon and nitrogen are depicted in Fig. 3 for different electrode spacings. These data demonstrate that the laser-induced gas breakdown (horizontal plasma column) effectively guides the discharge (between the screw and sample electrode) to a designated position on the sample electrode even when the gap length exceeds the length of laser-breakdown plasma. For example, in Fig. 3d, the length of the laser-induced plasma was $2 \mathrm{~cm}$ whereas the electrode spacing was $4 \mathrm{~cm}$. For the experimental parameters reported here, LGD lengths of $6 \mathrm{~cm}$ were possible in argon and nitrogen, however, a formative time lag occurred for these lengths in the nitrogen discharges.
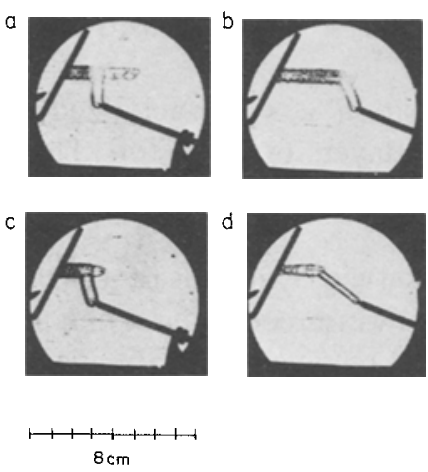

Fig. 3. Ruby laser schlieren photographs of laser guided discharges. ( $a, b)$ discharges in argon; ( $c, d)$ discharges in nitrogen. Data presented in Figs. 4, 5, and 7 obtained for the electrode spacing depicted in a and $\mathrm{c}$. The laserinduced breakdown plasma is indicated by the horizontal plasma column, and the discharge current path is indicated by the plasma path between the electrodes. 
Emission spectroscopy of argon and nitrogen LGD's revealed singly ionized atomic lines. Molecular and neutral atomic lines of nitrogen were not observed, nor were neutral argon lines. The time- and space-averaged electron temperature, determined from the ratios of several ion line intensities, was approximately $20,000 \mathrm{~K}$. The lines used to determine the electron temperature in argon were 4331, 4481, 4545, 4579, 4589, 4609, and $4657 \AA$. The lines used to determine the electron temperature in nitrogen were $3995,4041,4434$, and $4630 \AA$.

Figure 4 shows that the nitrogen discharges consistently were at higher electron temperatures than the argon discharges. The opacity of the LGD plasma was checked by comparing intensities of lines which originated from the same energy level, and it was determined that for these measurements the plasma was optically thin. The electron temperature increased with circuit capacitance for nitrogen, although for argon the electron temperature fluctuated within the error bounds $( \pm 1500 \mathrm{~K})$. Iron neutral lines (originating from the steel screw electrode) as well as aluminum neutral lines (from the foil) have also been observed.

A laser-guided discharge was performed in a mixture of helium and nitrogen in an attempt to measure the electron density by means of the Stark broadening of the He II $4686 \AA$ line. Based upon the parameters of Griem $^{(6)}$, the electron density was approximately $3.5 \times 10^{18} \mathrm{~cm}^{-3}$.

The temperature and density measurements reported here agree well with other studies. Raleigh and $\mathrm{Grieg}^{(7)}$ have estimated an electron temperature of $20,000 \mathrm{~K}$ and an electron density of $1.6 \times 10^{18} \mathrm{~cm}^{-3}$ for LGDs

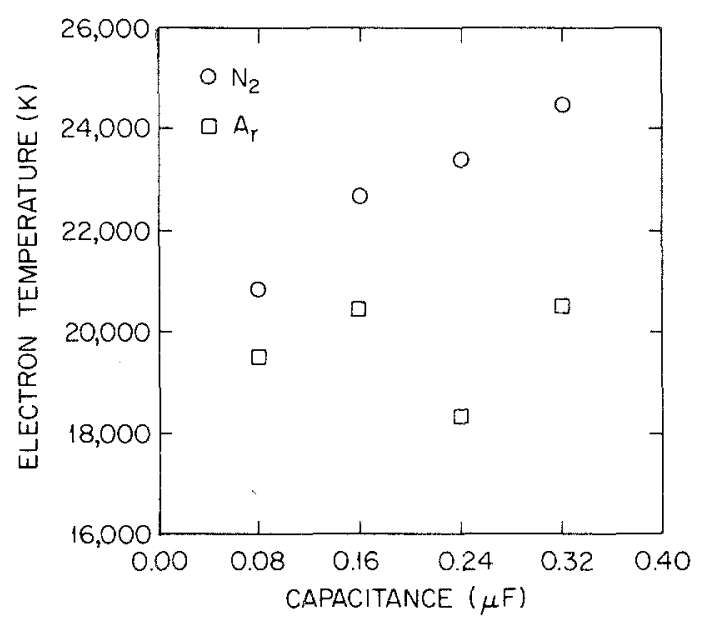

Fig. 4. Spectroscopically determined electron temperatures for laser-guided discharges in argon and nitrogen plotted as a function of discharge circuit capacitance. 


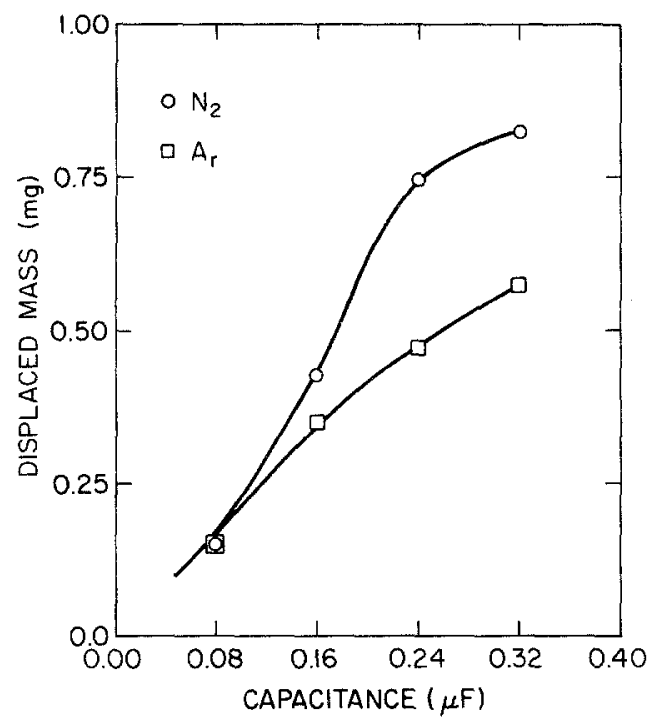

Fig. 5. Mass of aluminum foils displaced by laser-guided discharge melting as a function of discharge circuit capacitance. Each data point represents an average of about 10 shots.

at the Naval Research Lab. The parameters of our LGDs are similar to those of a lightning return stroke. Orville and others ${ }^{(8-12)}$ have measured both time-integrated and time-resolved spectra of lightning return strokes and have found an average electron temperature of $20,000-30,000 \mathrm{~K}$ and electron density of $10^{18} \mathrm{~cm}^{-3}$,

The effects of laser-guided discharges were examined on over 100 aluminum foil samples. An aluminum sample consisting of four layers of foil (each of thickness $16.8 \mu \mathrm{m}$ ) was placed over the stainless steel plate used as the sample electrode in the discharge circuit (see Fig. 1). Figure 5 shows that the degree of damage to each sample depended upon discharge gas and circuit capacitance. (The displaced mass was defined as the mass of aluminum contained in the volume of the holes generated in the foil layers.)

The LGDs in argon and nitrogen consistently produced holes in aluminum foils with diameters ranging from 1 to $6 \mathrm{~mm}$. These holes were uniform in both dimension and placement upon the foil (Fig. 6a). The holes were generally circular with the deviation in diameter from a perfect circle by $1 \mathrm{~mm}$ at most. (The diameter of each hole was measured to within $0.5 \mathrm{~mm}$.) Argon discharges produced slightly smaller holes than nitrogen discharges, with many more pinpoint spots and dents around the large center hole. The small spots and dents are believed to be due to small side arcs that deviate from the major arc path. These can be prevented by 


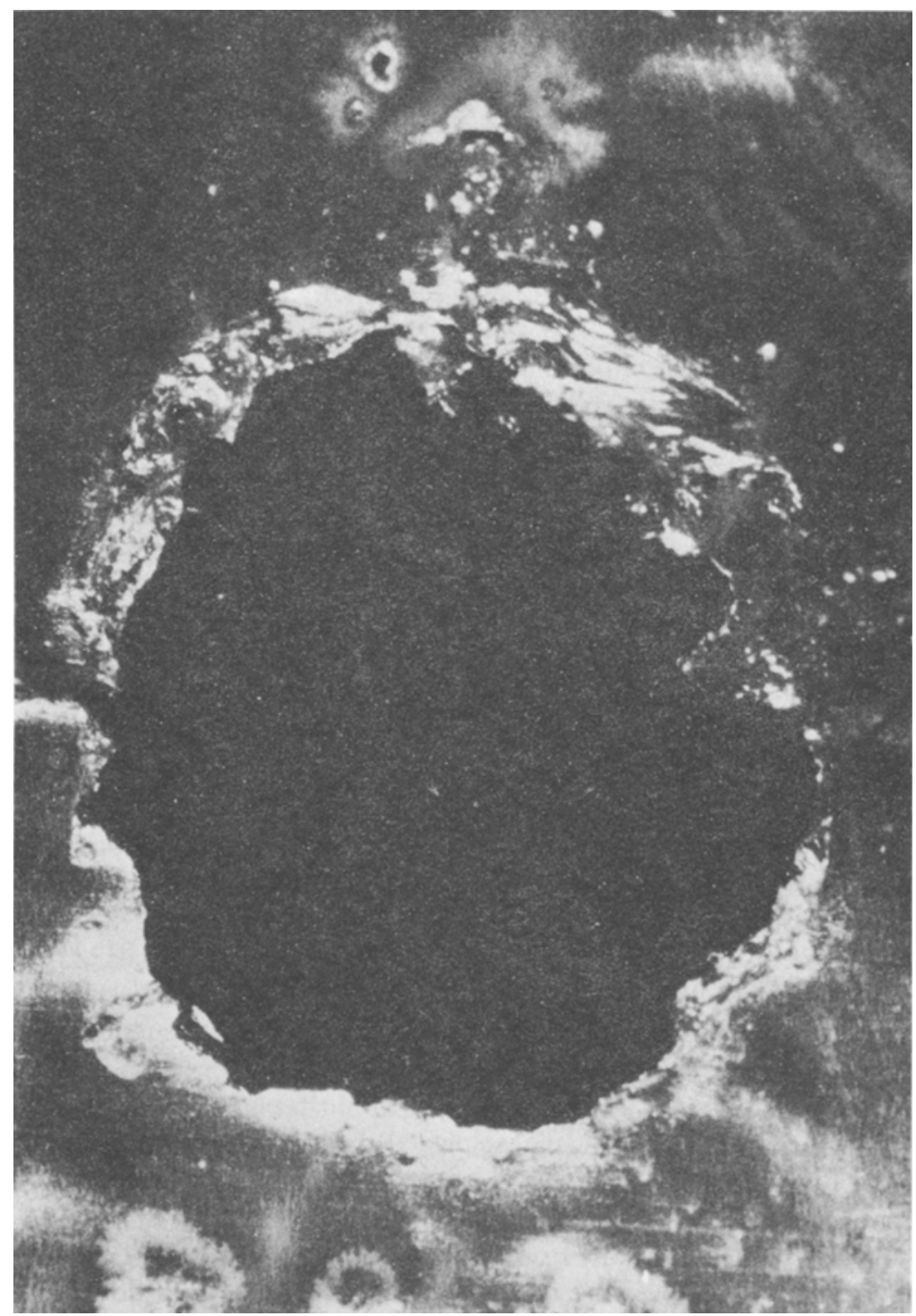

a

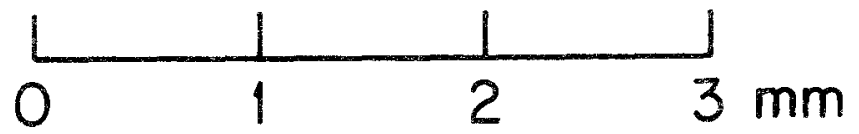

Fig. 6a. Hole bored in a $16.8-\mu \mathrm{m}$ aluminum foil by a nitrogen discharge with a capacitance of $0.16 \mu \mathrm{F}$. 
masking off the area by using an insulating material such as Mylar. Depending upon the capacitance, nitrogen discharges produced holes in both the top and second layer, whereas argon discharges produced a hole in the top layer only.

As the capacitance of the circuit was increased, the damage to the foils also increased, particularly in nitrogen (see Fig. 5). In addition to the holes in the first layer of foil becoming larger for increased capacitance, and holes appearing in the second layer, the degree of melting also increased. In the case of a capacitance of $0.24 \mu \mathrm{F}$, the first and second and/or second and third layers of the foil samples damaged by nitrogen plasmas were melted together around the center hole. For a capacitance of $0.32 \mu \mathrm{F}$, the second and third and/or third and fourth layers of the foil samples in nitrogen were melted together and one-third of the foil samples in argon were melted at the center between the first and second layers or else the second and third layers. Also, small spots of aluminum were stuck onto the electrode surface after several discharges.

The amount of damage to aluminum foils was also examined in helium, and it was discovered that helium discharges produced at most a few small pinholes in the foils. Schlieren pictures of these discharges suggested that helium LGDs were more diffuse than nitrogen and argon.

The distance between the electrodes was varied in argon and nitrogen LGDs, and the damage to aluminum foils was examined. There was no difference in the size of the holes produced in aluminum for distances between 2 and $6 \mathrm{~cm}$ in spite of the fact that the discharge current was delayed for distances of 5 and $6 \mathrm{~cm}$.

Experiments were also conducted on samples of other metals. A 3-mm hole was produced in a $12.5 \mu \mathrm{m}$ sample of copper foil. Localized heating was observed for $25-\mu \mathrm{m}$ foils of copper and iron, but holes were not formed. A large degree of damage was seen in titanium samples. A hole was produced in each layer $(12.5 \mu \mathrm{m})$ of a two-layer sample of titanium and Fig. $6 \mathrm{~b}$ shows a 3.5 -mm-diameter spot of titanium which was deposited from a single layer onto the stainless steel electrode. Samples of four foils of $12.5 \mu \mathrm{m}$ titanium experienced either a large hole in the first layer $(8 \mathrm{~mm})$ or else a pinpoint hole in the first layer with the first three layers melted together at the center. These results suggest that laser-guided discharges are a promising technique for welding and surface deposition of titanium in atmospheric-pressure gas.

An accounting of the energy balance to produce holes in aluminum foils is shown in Table I. The energy needed to heat the mass of the hole to the melting point of aluminum $(933 \mathrm{~K})$ is denoted $\Delta H_{\mathrm{mp}}$, the energy needed to melt the mass of the hole is denoted $\Delta H_{\text {melt }}$, and the energy needed to heat the hole to the boiling temperature $(2740 \mathrm{~K})$ is denoted $\Delta H_{\text {bp. }}$ 


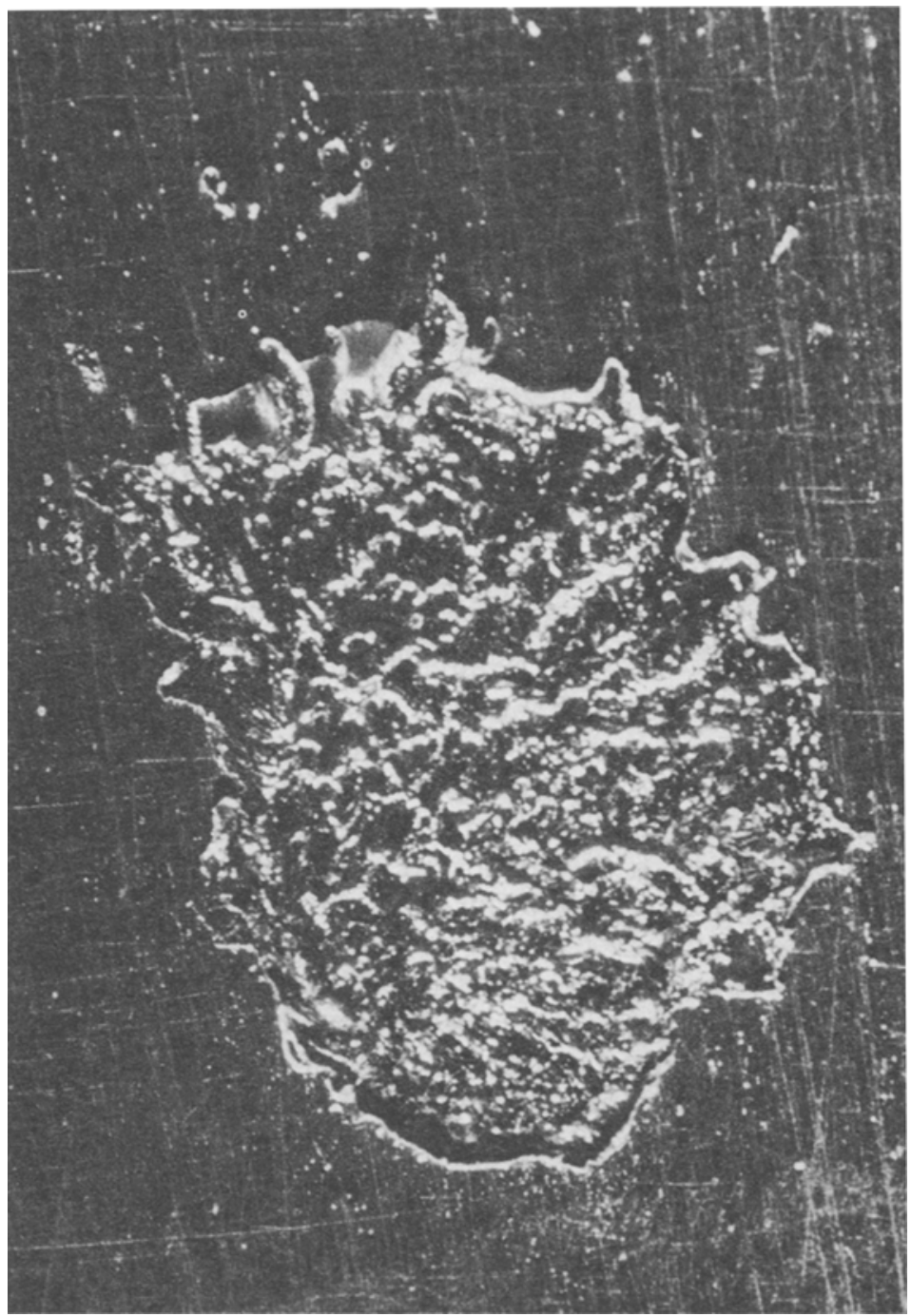

b

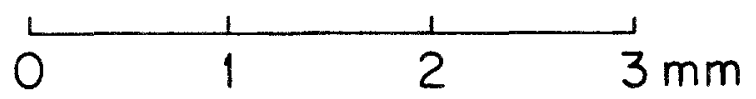

Fig. 6b. Photograph of $12.5-\mu \mathrm{m}$ titanium deposited on stainless steel sample. 
Table I. Energy Balance to Produce Holes in Aluminum ${ }^{a}$

\begin{tabular}{cccccc}
\hline Gas & Mass & $\Delta H_{\text {mp }}$ & $\Delta H_{\text {melt }}$ & $\Delta H_{\text {bp }}$ & $E_{\text {total }}$ \\
\hline $\mathrm{N}_{2}$ & $0.82 \mathrm{mg}$ & $0.47 \mathrm{~J}$ & $0.33 \mathrm{~J}$ & $1.61 \mathrm{~J}$ & $2.41 \mathrm{~J}$ \\
$\mathrm{Ar}$ & $0.57 \mathrm{mg}$ & $0.44 \mathrm{~J}$ & $0.23 \mathrm{~J}$ & $1.12 \mathrm{~J}$ & $1.68 \mathrm{~J}$ \\
\hline
\end{tabular}

${ }^{a}$ Capacitance $=0.32 \mu \mathrm{F}$, distance between electrodes $=2 \mathrm{~cm} . \Delta H_{\mathrm{mp}}=$ energy needed to heat the mass to the melting point. $\Delta H_{\text {melt }}=$ energy needed to melt the mass once it reaches the melting point. $\Delta H_{\mathrm{bp}}=$ energy needed to heat the mass from the melting point to the boiling point.

\section{MODELING OF SURFACE ENERGY DEPOSITION}

There are three principal mechanisms for energy deposition on metals from laser-guided discharges:

(1) Ohmic heating

(2) Surface recombination of dissociated diatomic molecules

(3) Thermal conduction from the plasma

Each of these energy deposition mechanisms is discussed below.

Due to the extremely high peak currents $(10-18 \mathrm{kA})$ of these laserguided discharges, even a small value of resistivity can result in significant ohmic energy (the integral of the resistance times the current squared over time). Our experiments have demonstrated that ohmic heating does occur, since in addition to the melted region on the front of the foil, we have also observed melted spots on the back of the foil samples at the point of electrical contact to the flat steel electrode. This damage on the rear of the foil could only be explained by ohmic heating since these melted regions were over $1 \mathrm{~cm}$ away from the focal spot of the LGD. Numerical estimates of ohmic heating energy are difficult because both the current and the temperature-dependent resistivity $\left(\rho_{\mathrm{Al}}=[2.655+0.004(T-20)] \mu \Omega \mathrm{cm}\right)$ change rapidly with time. Additionally, the current distribution in the sample must be accurately known; this is complicated since the current can flow radially outward on the foil as well as axially through the foil. If current is assumed to flow only radially outward in the foil, the ohmic energy deposition can be calculated. Assuming a Bennett current profile in the discharge and a discharge radius of $1 \mathrm{~mm}$, the ohmic energy deposited was estimated to be between 0.1 and $1 \mathrm{~J}$ depending on the capacitance of the circuit.

As can be seen in Fig. 7, the amount of mass displaced from the sample (hole size) increased as the ohmic energy increased. (Note that the ohmic energy is normalized here as the integral over time of the current squared.) It was found that nitrogen plasmas always produced more damage than 


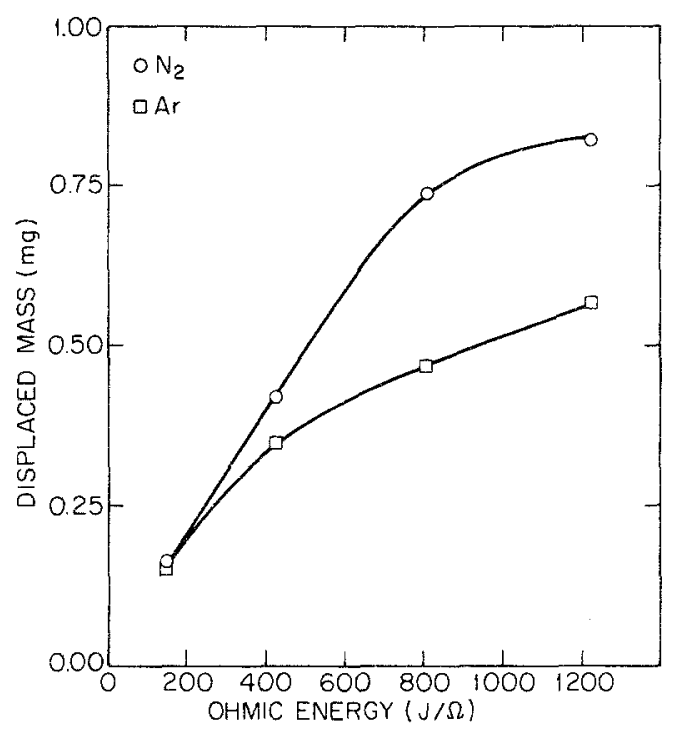

Fig. 7. Displaced mass data plotted as a function of normalized ohmic energy (defined as $\int i^{2} d t$ ).

argon plasmas. Current measurements taken for each shot show that there is no difference in the way the electrical energy is deposited for discharges in argon versus nitrogen; Ref. 13 indicates that there is no difference in the electrical conductivity of argon and nitrogen at $1 \mathrm{~atm}$ and electron temperatures near $20,000 \mathrm{~K}$. A major difference between the two gases, however, is the fact that the nitrogen molecules are dissociated in the discharge and then may recombine on the surface of the foil samples, adding chemical energy as well as ohmic energy.

To examine the degree to which surface recombination might occur, a simple chemical kinetic model was formulated. This model assumed that initially all of the nitrogen disssociates into atoms. This assumption is justified, since only atomic ion lines were observed in the time-integrated spectra. The model also assumes that the density and gas temperature remain constant for the duration of the neutral recombination $(5 \mu \mathrm{s}$ as determined from the model) and that the density is equal to the atmospheric density. Two types of neutral recombination were included in the model; the first is volume recombination:

$$
\mathrm{N}+\mathrm{N}+\mathrm{M} \rightleftarrows \mathrm{N}_{2}+\mathrm{M}
$$

where $M=N$ or $N_{2}$, and the second is surface recombination:

$$
\mathrm{N} \rightarrow \frac{1}{2} \mathrm{~N}_{2}
$$


The forward rate $k_{1}\left[3.0 \times 10^{14} \exp (500 / T) \mathrm{cm}^{6} \mathrm{~mole}^{-2} \mathrm{~s}^{-1}\right]$ and backward rate $k_{2}\left[3.7 \times 10^{21} T^{-1.6} \exp (-113,200 / T) \mathrm{cm}^{3} \mathrm{~mole}^{-1} \mathrm{~s}^{-1}\right]$ coefficients were those recommended by Baulch et al. ${ }^{(14)}$ for $\mathrm{M}=\mathrm{N}_{2}$. It was assumed that the rates for $\mathrm{M}=\mathrm{N}\left(k_{3}\right.$ and $\left.k_{4}\right)$ were equal to four times $k_{1}$ and $k_{2}$. The recombination coefficient $\gamma$ (the ratio of the frequency of collisions of atoms with the surface leading to recombination to the total frequency of collisions) depends not only upon the type of surface material, but upon the condition of the surface as well. Typical values of $\gamma$ for metals range from 0.01 to $1{ }^{(15)}$ For this model, cases were examined for several different values of $\gamma$ (see Fig. 8).

The concentrations of atomic and molecular nitrogen as a function of time can be calculated by solving the following two equations:

$$
\begin{gathered}
d\left[\mathrm{~N}_{2}\right] / d t=k_{1}[\mathrm{~N}]^{2}\left[\mathrm{~N}_{2}\right]-k_{2}\left[\mathrm{~N}_{2}\right]^{2}+k_{3}[\mathrm{~N}]^{3}-k_{4}\left[\mathrm{~N}_{2}\right][\mathrm{N}]+1 / 2 k_{5}[\mathrm{~N}] \\
d[\mathrm{~N}] / d t=-2\left(d\left[\mathrm{~N}_{2}\right] / d t\right)
\end{gathered}
$$

Note that $k_{5}=1.92 \times 10^{3} \mathrm{~T} \mathrm{sec}^{-1}$ for the geometry of a nitrogen cylindrical plasma with a surface at one end. The two differential equations were solved by a differential equation solver called EPISODE. ${ }^{(16)}$ The degree of surface and volume recombination contributing to the recombination of the atoms was also calculated. The amount of energy deposited to the sample surface as a function of plasma gas temperature is plotted in Fig. 8 for several different values of $\gamma$. The dotted line at $0.73 \mathrm{~J}$ represents the energy deposition difference between nitrogen and argon plasmas as calculated

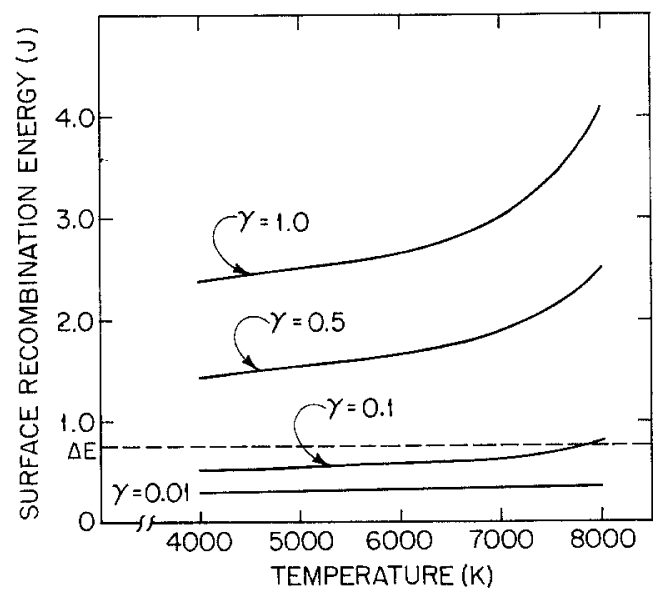

Fig. 8. Predictions of computer model for surface recombination energy of nitrogen at various gas temperatures. Dashed line represents the estimated experimental difference in energy deposition between laser-guided discharges in nitrogen versus argon (see Table I). 
from Table I. This value matches the surface recombination energy well (for $\gamma=0.1$ ) at a temperature of $7000-8000 \mathrm{~K}$, the ion (and neutral) temperature of the plasma for the first few microseconds as suggested by Raleigh and Greig ${ }^{(7)}$ based upon air-chemistry simulation codes. The model also predicted that the majority of the atoms recombine in 3-5 $\mu \mathrm{s}$.

Thermal conduction can also transfer energy from the discharge plasma to the metal sample. We have measured the volume of aluminum melted by LGD for different discharge lengths ranging from 2 to $6 \mathrm{~cm}$. These results showed little variation in deposited energy as a function of discharge length, suggesting that any thermal conduction energy is supplied only by the plasma near the sample electrode surface. Theoretical estimates of this thermal conduction energy are not given here since these would require detailed data concerning the plasma temperature and temperature gradients near the metal surface.

\section{DISCUSSION AND CONCLUSIONS}

In examining the suitability of a metal for LGD welding or hole boring, at least two properties of the metal must be considered:

(1) The efficiency of energy deposition into the sample

(2) The amount of energy necessary to produce the desired effect

The first depends upon the material's resistivity and thermal conductivity, as well as the surface recombination coefficient. An estimate of the overall efficiency for hole boring in aluminum for the data presented here can be calculated by

$$
\text { Efficiency }=E_{\text {total }} /\left(E_{\mathrm{i}}-E_{\mathrm{f}}\right)
$$

where $E_{\text {total }}=\Delta H_{\mathrm{mp}}+\Delta H_{\text {melt }}+\Delta H_{\mathrm{bp}}$ as defined in Table $\mathrm{I}$ and $E_{\mathrm{i}}$ is the initial stored energy in the capacitors; $E_{\mathrm{f}}$ is the final energy stored in the capacitor after the discharge interupts. The efficiencies range from 1.2 to $2.6 \%$ depending upon the number of capacitors and type of gas. (Nitrogen gives higher efficiencies than argon.) $\mathrm{CO}_{2}$ lasers used in welding and materials processing have efficiencies ranging from 5 to $15 \%{ }^{(17)}$ This efficiency is further reduced due to losses in coupling $\mathrm{CO}_{2}$ light to highreflectivity materials.

The second property depends upon a combination of density, specific heat, and melting temperature. Table II lists the resistivity, density, thermal conductivity, and melting temperature of aluminum, copper, iron, and titanium, as listed in Ref. 18. Also included in Table II are the results of similar calculations to those of Table I, assuming a 4-mm hole in one foil with a thickness of $12.5 \mu \mathrm{m}$. The largest amount of damage was observed 
Table II. Density, Resistivity, Thermal Conductivity, Melting Temperature, and Energy Needed to Produce a 4-mm Hole in $\mathrm{Al}, \mathrm{Cu}, \mathrm{Fe}$, and $\mathrm{Ti}$

\begin{tabular}{cccccc}
\hline Metal & $\begin{array}{c}\text { Density } \\
\left(\mathrm{g} / \mathrm{cm}^{3}\right)\end{array}$ & $\begin{array}{c}\text { Resistivity }^{a} \\
(\mu \Omega \mathrm{cm})\end{array}$ & $\begin{array}{c}\text { Thermal } \\
\text { conductivity }^{a} \\
\left(\mathrm{~W} / \mathrm{cm}^{\circ} \mathrm{C}\right)\end{array}$ & $\begin{array}{c}\mathrm{T}(\mathrm{melting}) \\
\left({ }^{\circ} \mathrm{C}\right)\end{array}$ & Energy $(\mathrm{J})$ \\
\hline $\mathrm{Al}$ & 2.71 & 2.65 & 2.37 & 660 & 1.15 \\
$\mathrm{Cu}$ & 8.92 & 1.67 & 3.98 & 1083 & 1.78 \\
$\mathrm{Fe}$ & 7.86 & 9.71 & 0.80 & 1535 & 2.54 \\
$\mathrm{Ti}$ & 4.52 & 42.0 & 0.2 & 1675 & 1.32 \\
\hline
\end{tabular}

${ }^{a}$ Resistivity and thermal conductivity at $25^{\circ} \mathrm{C}$.

in titanium, which is consistent with a high resistivity and small amount of energy necessary to produce a hole, in spite of the high melting temperature. Aluminum, which also showed substantial damage compared to iron and copper, has a low melting temperature; a smaller amount of energy was required to bore holes in aluminum compared to iron and copper, in spite of the fact that it also has a low resistivity and high thermal conductivity. The data of Table II agree qualitatively with our experimental observations. Further research is required concerning the parameters which affect melting and hole boring in different types of metals.

\section{ACKNOWLEDGMENTS}

We express our gratitude to P. Weber for photographing the samples. This research was supported by the U.S. Office of Naval Research under Project 81-K-0700 and the National Science Foundation Grant ECS 8105966.

\section{REFERENCES}

1. J. R. Greig, D. W. Koopman, R. F. Fernsler, R. E. Pechacek, I. M. Vitkovitsky, and A. W. Ali, Phys. Rev. Lett. 41, 174 (1978).

2. D. W. Koopman, J. R. Greig, R. E. Pechacek, A. W. Ali, I. M. Vitkovitsky, and R. F. Fernsler, J. Phys. (Paris) Colloq. Suppl. 7 40, 419 (1979).

3. D. W. Koopman and K. A. Saum, J. Appl. Phys. 44, 5328 (1973).

4. K. A. Saum and D. W. Koopman, Phys. Fluids 15, 2077 (1972).

5. R. M. Gilgenbach, O. E. Ulrich, and L. D. Horton, Rev. Sci. Instrum. 54, 109 (1983).

6. H. Griem, Plasma Spectroscopy, McGraw Hill, New York (1964), p. 538.

7. M. Rayleigh and J. R. Greig, NRL Memorandum Report 4556, May 1982.

8. R. E. Orville, Chapter 8, Lightning Spectroscopy, in Lightning, Vol. I. R. H. Golde, ed., Academic Press, New York (1977).

9. M. L. Prueitt, J. Geophys. Res. 68, 803 (1963).

10. R. E. Orville and L. E. Salanave, Appl. Opt. 9, 1775 (1970). 
11. M. A. Uman and R. E. Orville, J. Geophys. Res. 69, 5151 (1964).

12. R. D. Hill, J. Geophys. Res. 76, 637 (1971).

13. M. W. Thring, Plasma Engineering, in Properties and Applications of Low-Temperature Plasma, Plenum Press, New York (1966).

14. D. L. Baulch, D. P. Drysdale, D. G. Horne, and A. C. Lloyd, Evaluated Kinetic Data for High-Temperature Reactions, Vol. II, Homogeneous Gas-Phase Reactions of $\mathrm{H}_{2}-\mathrm{N}_{2}-\mathrm{O}_{2}$ System, Butterworths, London (1973).

15. M. L. Rahman and J. W. Linnett, Trans. Faraday Soc. 67, 183 (1971).

16. A. C. Hindmarsh and G. D. Bryne, EPISODE: An Experimental Package for the Integration of Systems of Ordinary Differential Equations, Lawrence Livermore Laboratory, UCID30112, May 1975.

17. George Bekefi, editor, Principles of Laser Physics, John Wiley, New York (1976), p. 4.

18. Handbook of Chemistry and Physics, 51st edn., The Chemical Rubber Co., Cleveland (1970). 